\title{
(6) OPEN ACCESS \\ Strategies and factors associated with preparing for competing in the heat: a cohort study at the 2015 IAAF World Athletics Championships
}

\author{
Julien D Périard, ${ }^{1}$ Sébastien Racinais, ${ }^{1}$ Toomas Timpka, ${ }^{2}$ Örjan Dahlström, ${ }^{2}$ \\ Armin Spreco, ${ }^{2}$ Jenny Jacobsson, ${ }^{2,3}$ Victor Bargoria, ${ }^{2,4}$ Karin Halje, $^{2,5}$ \\ Juan-Manuel Alonso ${ }^{6}$
}

\begin{abstract}
- Additional material is published online only. To view please visit the journal online (http://dx.doi.org/10.1136/ bjsports-2016-096579).

${ }^{1}$ Athlete Health and Performance Research Centre, Aspetar Orthopaedic and Sports Medicine Hospital, Doha, Qatar

${ }^{2}$ Athletics Research Center, Linköping University, Linköping, Sweden

${ }^{3}$ Swedish Athletics Association, Stockholm, Sweden

${ }^{4}$ Department of Orthopaedics and Rehabilitation,

Moi University, Eldoret, Kenya ${ }^{5}$ Young Adults Centre, Region Östergötland, Linköping, Sweden

${ }^{6}$ Sports Medicine Department, Aspetar Orthopaedic and Sports Medicine Hospital, Doha, Qatar
\end{abstract}

Correspondence to Dr Julien Périard, Athlete Health and Performance Research Centre, Aspetar Orthopaedic and Sports Medicine Hospital, P.O. Box 29222, Doha, Qatar; julien.periard@aspetar.com

Accepted 17 October 2016 Published Online First 4 November 2016

\begin{abstract}
Purpose Assess exertional heat illness (EHI) history and preparedness in athletes competing in a World Athletics Championships under hot/humid conditions and identify the factors associated with preparedness strategies. Methods of the 207 registered national teams invited to participate in the study, 50 (24\%) accepted. The 957 athletes (49\% of all 1965 registered) in these teams were invited to complete a precompetition questionnaire evaluating EHI history, heat stress prevention (heat acclimatisation, precooling and hydration) and recovery. Responses from 307 (32\%) athletes were separated in field events, sprints, middle-distance and long-distance running, and decathlon/heptathlon for analysis.
\end{abstract}

Results $48 \%$ of athletes had previously experienced EHI symptoms and $8.5 \%$ had been diagnosed with EHI. $15 \%$ heat acclimatised ( 20 days) before the championships. $52 \%$ had a precooling strategy, ice slurry ingestion (24\%) being the most prevalent and women using it more frequently than men $(p=0.005) .96 \%$ of athletes had a fluid consumption strategy, which differed between event categories $(p<0.001)$. The most common volumes planned on being consumed were $0.5-1 \mathrm{~L}$ $(27.2 \%)$ and $\geq 2 \mathrm{~L}(21.8 \%)$, water being the most frequent. $89 \%$ of athletes planned on using at least one recovery strategy. Female sex $(p=0.024)$ and a previous EHI diagnosis increased the likelihood of using all 3 prevention strategies $(p<0.001)$.

Conclusions At a World Championships with expected hot/humid conditions, less than one-fifth of athletes heat acclimatised, half had a precooling strategy and almost all a hydration plan. Women, and especially athletes with an EHI history, were more predisposed to use a complete heat stress prevention strategy. More information regarding heat acclimatisation should be provided to protect athlete health and optimise performance at major athletics competitions in the heat.

\section{INTRODUCTION}

The 15th International Association of Athletics Federations (IAAF) World Championships were held in Beijing (China) from 22 to 30 of August 2015. Based on weather patterns from the previous 10 years, it was anticipated that the event would be held in warm/hot and humid conditions, with mean and maximum daily temperatures of $\sim 26^{\circ} \mathrm{C}$ and $\sim 33^{\circ} \mathrm{C}$, respectively, and a relative humidity of $\sim 73 \% .^{1}$ Under such environmental conditions, there is potential for both the performance and health of athletes to be compromised, leading to impairments in exercise capacity and possibly to exertional heat illness (EHI).

From a performance perspective, the influence of hot environmental conditions is largely related to exercise duration. For example, an increase in core and particularly muscle temperature is beneficial to performance (ie, the production of maximal force and power) during brief explosive efforts such as jumping and sprinting. ${ }^{2}$ In contrast, large increments in core and skin temperature (ie, thermal strain) are associated with impaired endurance performance due to an increase in thermoregulatory function exacerbating the cardiovascular response. ${ }^{34}$ Severe dehydration via excessive sweating further exacerbates the influence of heat stress on performance through a loss of plasma volume, causing hypovolaemia. ${ }^{5}$

The development of EHI may be viewed as occurring along a continuum, from relatively mild symptoms such as muscle cramps to heat exhaustion and to the more serious and life-threatening condition of exertional heatstroke. ${ }^{6} 7$ Although hyperthermia and dehydration can influence aerobic performance and lead to EHI, specific interventions such as heat acclimatisation and precooling can allow athletes to minimise the loss in performance associated with competing in hot ambient conditions. ${ }^{8}$ The IOC recently highlighted the need to characterise the sport and event-specific profiles of international athletes competing in the heat in a consensus statement. ${ }^{9}$ Indeed, while core temperature and heart rate have been monitored in amateur runners during a half-marathon ${ }^{10}$ and the impact of weather on marathon performance has been described for different populations, ${ }^{11}$ it remains unknown whether elite track and field athletes follow so-called 'best practice' approaches when preparing to compete in the heat Understanding how elite athletes from various disciplines and global regions prepare for a major competition in the heat may help guide future practice and research.

Therefore, this study aimed to assess the EHI history, preparedness and recovery of athletes competing in the championships under potentially hot/ humid conditions, as well as to identify the factors associated with different preparedness strategies. Preparation was assessed based on the athletes training in the heat prior to the championships, along with using precooling and fluid consumption strategies during competition. It was hypothesised 
that individuals having experienced EHI and athletes competing in endurance-type events would more commonly adopt heat stress prevention strategies.

\section{METHODS}

\section{Participants}

A cohort study design was used to collect data during the IAAF World Athletics Championships in Beijing 2015. Of the 207 registered national teams invited to participate in the study, 50 (24\%) accepted. The 957 athletes in these teams (49\% of the 1965 registered athletes) were invited to complete a precompetition heat strategy questionnaire. Information about the purpose of the study was provided to the athletes during the accreditation procedure. A total of 307 (32\%) athletes accepted to participate. The athletes were separated in five event categories: field (ie, jumps and throws), sprints (ie, 100, 200, $400 \mathrm{~m}$, including hurdles and relays), middle distance (ie, 800, 1500 and $3000 \mathrm{~m}$ steeplechase), long distance (ie, 5000 and $10000 \mathrm{~m}$, marathon and race walking) and decathlon/heptathlon. The characteristics of the athletes in each event category are presented in table 1 . The protocol for the study was approved by the Anti-Doping Lab Qatar Institutional Review Board (F2015000074). All procedures conformed to the standards of the Declaration of Helsinki.

\section{Data collection}

Participants completed a precompetition heat strategy questionnaire in the days prior to competing in their event after arriving in Beijing. The questionnaire was translated into the six IAAF official languages (English, French, Russian, Japanese, Spanish and Arabic). The questionnaire consisted of seven multiplechoice questions addressing the themes of heat illness, heat acclimatisation ( $\leq 35$ days), cooling, hydration and recovery (see online supplementary appendix). Five of the questions had a section with the possibility for additional information to be provided. The questionnaire was intended to gain an understanding of the approach used by elite athletes and their coaches ahead of a major competition likely to be held in hot and humid conditions. The questionnaire focused on strategies used in the preparation, competition and recovery phases of the championships. Participating athletes completed the questionnaire on print paper, after receiving instructions from on-field researchers. In-championship heat illness was defined according to the consensus on injury and illness reporting in athletics. ${ }^{12}$ Newly incurred injuries and illnesses were recorded by national medical teams and/or by physicians on the local organising committee using procedures established at previous championships. $^{13}{ }^{14}$ Ambient air temperature and Wet Bulb Globe

Table 1 Characteristics of the precompetition heat-strategy questionnaire responders from 50 different national teams during the 2015 IAAF World Championships

\begin{tabular}{llccc}
\hline Discipline categories & $\begin{array}{l}\text { Number of } \\
\text { responders }\end{array}$ & Male & Female & Age (year) \\
\hline Field events & 76 & 41 & 35 & $27 \pm 5$ \\
Sprints and hurdles & 88 & 49 & 39 & $25 \pm 4$ \\
Middle distance & 37 & 21 & 16 & $26 \pm 3$ \\
Long distance & 94 & 53 & 41 & $29 \pm 5$ \\
Decathlon/heptathlon & 12 & 8 & 4 & $27 \pm 4$ \\
Total/mean & 307 & 172 & 135 & $27 \pm 5$ \\
\hline
\end{tabular}

IAAF, International Association of Athletics Federations.
Temperature (WBGT: Kestrel 4400, Nielsen-Kellerman, Boothwyn, USA) were measured in the warm-up area and stadium throughout each day for the duration of the championships, as well as during the marathon and race walking events.

\section{Definition of heat stress prevention}

Four different measures of heat stress prevention were defined: (1) 'Having trained in the heat before the championships', (2) 'Planning to use a precooling method before the competition', (3) 'Planning to consume fluids during the competition', and (4) 'All of (1), (2) and (3)'.

\section{Statistical analysis}

Differences of proportions of heat stress prevention strategies over different home continent, sex and event category were examined using $\chi^{2}$ tests with $\phi$ as effect size $(\phi=0.1$ was considered a small effect, $\phi=0.3$ a medium effect and $\phi=0.5$ a large effect). An analysis of non-participating athletes was performed by comparing their distribution of home continent, the Human Development Index (HDI), ${ }^{15}$ sex and age with the final study group. Examination of potential factors explaining the use of heat stress prevention strategies at the championship was performed using logistic regression analysis. First, analyses were performed with simple models (ie, logistic regression analyses with 1 explanatory variable). Thereafter, analyses were performed with multiple models (ie, logistic regression analyses with several explanatory variables) for each of the four definitions of heat stress prevention. The multiple models were fitted using stepwise elimination of non-significant variables. The explanatory variables were sex, age, home continent, the HDI, event category, availability of medical support before the championships, experience of previous heat-related symptoms, and previously having been diagnosed with EHI. Events for these models were coded into two categories: speed/power (field, sprints and decathlon/heptathlon) and endurance (middle and long distance) events. All statistical calculations were performed using SPSS Statistics for Windows, V.21.0 (IBM Corporation, Armonk, New York, USA). All statistical tests were two-sided and outcomes with $\mathrm{p}<0.05$ were regarded as statistically significant. Data are presented as mean \pm SD.

\section{RESULTS}

The distribution of athletes completing the questionnaire per continent was 11.1\% from Africa, 18.2\% from Asia, 2.6\% from Australia, 32.9\% from Europe, 14.3\% from North America and 20.8\% from South America. A comparison of the participating and non-participating athletes revealed that while sex showed no significant difference between groups, non-participation was slightly higher in athletes over 25 years $(p=0.040)$, in African athletes $(p<0.001)$ and among athletes from developing countries according to the HDI $(p=0.037)$.

\section{Environmental conditions and EHI}

Mean daily temperature and WBGT during the championships were $27 \pm 3^{\circ} \mathrm{C}$ and $24 \pm 2^{\circ} \mathrm{C}$ at $8: 00,31 \pm 3^{\circ} \mathrm{C}$ and $27 \pm 2^{\circ} \mathrm{C}$ at $12: 00$, and $30 \pm 4^{\circ} \mathrm{C}$ and $25 \pm 2^{\circ} \mathrm{C}$ at $16: 00$. Five (1.6\%) of the athletes participating in the study were diagnosed with symptoms (eg, nausea, vomiting, dizziness, palpitations and syncope) associated with EHI (eg, exhaustion, dehydration) during the championships.

\section{Heat illness symptoms and diagnosis}

Approximately half (47.6\%) of the athletes responding to the questionnaire reported having previously experienced at least 
Table 2 Previous history of symptoms and diagnosis of heat illness in athletes (\% of responders) competing in the 2015 IAAF World Championships

\begin{tabular}{|c|c|c|c|c|c|}
\hline & Field & Sprints & $\begin{array}{l}\text { Middle } \\
\text { distance }\end{array}$ & $\begin{array}{l}\text { Long } \\
\text { distance }\end{array}$ & $\begin{array}{l}\text { Decathlon/ } \\
\text { heptathlon }\end{array}$ \\
\hline \multicolumn{6}{|c|}{ History of heat illness symptoms } \\
\hline Cramping & 27.6 & 26.1 & 16.2 & 25.5 & 33.3 \\
\hline Vomiting & 7.9 & 20.5 & 8.1 & 10.6 & 16.7 \\
\hline Nausea & 9.2 & 17.0 & 8.1 & 13.8 & 16.7 \\
\hline Severe headache & 14.5 & 22.7 & 29.7 & 11.7 & 33.3 \\
\hline Collapsing/fainting & 3.9 & 3.4 & 5.4 & 9.6 & 0.0 \\
\hline Other & \multicolumn{5}{|c|}{ Dizziness, tiredness, gastrointestinal issues, tachycardia } \\
\hline \multicolumn{6}{|c|}{ History of heat illness diagnosis } \\
\hline Dehydration & 5.3 & 2.3 & 5.4 & 5.3 & 8.3 \\
\hline Hyponatraemia & 0.0 & 0.0 & 0.0 & 0.0 & 0.0 \\
\hline Heat exhaustion & 1.3 & 1.1 & 0.0 & 3.2 & 8.3 \\
\hline Heat stroke & 0.0 & 3.4 & 0.0 & 2.1 & 0.0 \\
\hline
\end{tabular}

one heat illness symptom, whereas $17 \%$ reported two or more symptoms (table 2). Event category influenced the prevalence of experiencing severe headaches during training and/or competing in the heat $(p=0.049, \phi=0.18)$, with a greater fraction of middle-distance runners and decathlon/heptathlon athletes reporting this symptom. Nausea $(p=0.065, \phi=0.11)$ and severe headaches $(p=0.079, \phi=0.10)$ tended to be symptoms more often reported in women than men during training and/or competing in the heat. Of the 26 athletes $(8.5 \%)$ reporting a previous diagnosis of EHI, $3(11.5 \%)$ reported having been diagnosed with both dehydration and heat exhaustion.

\section{Heat training}

In preparation for the championships, $15.3 \%$ of the athletes surveyed reported having prepared specifically by training in the heat. No significant differences in heat acclimatisation were observed for home continent, sex and event category. In the field events, $15.8 \%$ of athletes trained in a natural hot environment, $17.0 \%$ of sprint athletes, $13.5 \%$ of middle-distance athletes, $12.8 \%$ of long-distance athletes and $16.7 \%$ of decathlon/ heptathlon athletes also reported following a heat acclimatisation regimen. The length of the regimen varied between $17 \pm 10$ days (field events), $18 \pm 10$ days (sprints), $18 \pm 11$ days (middle distance), $23 \pm 10$ days (long distance) and $30 \pm 0$ days (decathletes/ heptathletes). In addition, two long-distance athletes reported training indoors in an artificially hot environment (ie, heat acclimation) for 11 and 12 days, respectively.

\section{Precooling}

Approximately half $(52.4 \%)$ of the athletes reported having at least one prearranged cooling strategy, $10.4 \%$ having two strategies and $4.9 \%$ having three strategies (table 3 ). Event category influenced the use (or not) of a strategy $(p=0.012, \phi=0.19)$, as well as use of an ice vest $(p<0.001, \phi=0.32)$, with a small-to-medium effect on the use of a neck collar $(p=0.055$, $\phi=0.17)$ and whole-body cold-water immersion $(p=0.074$, $\phi=0.17)$. Women reported using ice slurry or cold drink ingestion $(p=0.005, \phi=01.6)$ and neck collars $(p=0.050, \phi=0.11)$ more frequently than did men.

\section{Hydration}

The analysis revealed differences among event categories for the volume of fluids planned on being consumed $(\mathrm{p}<0.001$,
Table 3 Prearranged cooling, hydration and recovery strategies in athletes (\% of responders) competing in the 2015 IAAF World Championships

\begin{tabular}{|c|c|c|c|c|c|}
\hline & Field & Sprints & $\begin{array}{l}\text { Middle } \\
\text { distance }\end{array}$ & $\begin{array}{l}\text { Long } \\
\text { distance }\end{array}$ & $\begin{array}{l}\text { Decathlon/ } \\
\text { heptathlon }\end{array}$ \\
\hline \multicolumn{6}{|c|}{ Precooling methods athletes planned on using } \\
\hline None & 61.8 & 46.6 & 29.7 & 43.6 & 50.0 \\
\hline Ice vest & 0.0 & 0.0 & 5.4 & 17.0 & 16.7 \\
\hline Cold towel & 15.8 & 10.2 & 18.9 & 11.7 & 33.3 \\
\hline Neck collar & 0.0 & 3.4 & 10.8 & 3.2 & 8.3 \\
\hline Whole-body CWI & 1.3 & 3.4 & 10.8 & 8.5 & 8.3 \\
\hline Leg CWI & 13.2 & 12.5 & 24.3 & 10.6 & 25.0 \\
\hline Ice slurry ingestion & 15.8 & 28.4 & 21.6 & 25.5 & 41.7 \\
\hline Other & \multicolumn{5}{|c|}{ Cold hat/cap, cold water, ice-massage } \\
\hline \multicolumn{6}{|l|}{ Planned fluid consumption } \\
\hline None & 0.0 & 13.6 & 37.8 & 23.4 & 0.0 \\
\hline$<0.5 \mathrm{~L}$ & 6.6 & 9.1 & 2.7 & 10.6 & 0.0 \\
\hline $0.5-1 \mathrm{~L}$ & 43.4 & 34.1 & 18.9 & 11.7 & 0.0 \\
\hline $1-1.5 \mathrm{~L}$ & 21.1 & 19.3 & 8.1 & 14.9 & 8.3 \\
\hline $1.5-2 \mathrm{~L}$ & 11.8 & 13.6 & 16.2 & 11.7 & 0.0 \\
\hline$>2 \mathrm{~L}$ & 17.1 & 10.2 & 16.2 & 27.2 & 91.7 \\
\hline \multicolumn{6}{|l|}{ Planned fluid composition } \\
\hline Water & 90.8 & 78.4 & 78.4 & 62.8 & 91.7 \\
\hline Electrolytes & 35.5 & 44.3 & 35.1 & 58.5 & 75.0 \\
\hline Carbohydrates & 7.9 & 8.0 & 16.2 & 30.9 & 58.3 \\
\hline Other & \multicolumn{5}{|c|}{ Cold tea, green tea, protein, Red Bull, Gatorade } \\
\hline \multicolumn{6}{|l|}{ Planned recovery strategies } \\
\hline None & 15.8 & 1.1 & 0.0 & 11.7 & 0.0 \\
\hline Active recovery & 31.6 & 47.7 & 59.5 & 41.5 & 66.7 \\
\hline Stretching & 43.4 & 51.1 & 48.6 & 46.8 & 66.7 \\
\hline Contrast immersion & 3.9 & 8.0 & 13.5 & 10.6 & 8.3 \\
\hline CWI & 26.3 & 45.5 & 59.5 & 35.1 & 66.7 \\
\hline Massage & 56.6 & 55.7 & 67.6 & 48.9 & 50.0 \\
\hline Hot water immersion & 6.6 & 8.0 & 10.8 & 5.3 & 8.3 \\
\hline Electrostimulation & 5.3 & 2.3 & 2.7 & 1.1 & 16.7 \\
\hline Compression clothing & 7.9 & 9.1 & 18.9 & 20.2 & 8.3 \\
\hline Other & \multicolumn{5}{|c|}{ Icing, cryotherapy, protein, pool recovery } \\
\hline
\end{tabular}

CWI, cold-water immersion; IAAF, International Association of Athletics Federations.

$\phi=0.56)$. The most commonly reported volumes were $0.5-1 \mathrm{~L}$ (27.2\%) and $2 \mathrm{~L}$ or more $(21.8 \%$; table 3$)$. The preferred fluid composition for hydration was water, with medium-to-large differences for drinking water $(p<0.001, \phi=0.26)$, electrolytes $(\mathrm{p}=0.004, \phi=0.22)$ and carbohydrates $(\mathrm{p}<0.001, \phi=0.34)$ between event categories. Women preferred to consume water more than men $(p=0.016, \phi=0.14)$.

\section{Recovery}

Most athletes planned on only using one recovery strategy (26.1\%), with $23.5 \%, 17.9 \%$ and $13.7 \%$ planning on using two, three and four strategies, respectively, while $7.5 \%$ planned on using five or more recovery strategies (table 3 ). There were differences between event categories in the use (or not) of recovery strategies $(p=0.001, \phi=0.24)$, including active recovery $(p=0.021, \phi=0.19)$, cold-water immersion $(p=0.002$, $\phi=0.24)$, electrostimulation $(p=0.049, \phi=0.18)$ and compression garments $(p=0.078, \phi=0.17)$. Women reported planning the use of recovery strategies more frequently than men $(p=0.017, \phi=0.14)$, with a greater use of massage therapy $(p=0.025, \phi=0.13)$. 


\section{Explanatory models}

The simple model analyses showed that sex (females: $20.0 \%$, males: $11.6 \%$ ) (odds ratio (OR) 1.90; $\mathrm{p}=0.045$ ), a history of experiencing heat illness symptoms $(\mathrm{OR} 1.88 ; \mathrm{p}=0.048)$ and $\mathrm{a}$ previous diagnosis of EHI (OR 7.27; $\mathrm{p}<0.001)$ increased the likelihood of training in the heat prior to the championships (table 4). In the multiple model, only the associations between the sex of the athlete and previous EHI diagnosis remained.

The simple model analyses showed that precooling was influenced by sex (females: $57.8 \%$ and males: $48.3 \%$ ) (OR 1.64; $\mathrm{p}=0.034)$, event category (OR 1.72; $\mathrm{p}=0.020)$, continent $(\mathrm{p}<0.001)$, HDI $(\mathrm{OR} 2.44 ; \mathrm{p}<0.001)$ and having previously been diagnosed with EHI (OR 2.73; $\mathrm{p}=0.023$ ) (table 5). Athletes originating from Asia demonstrated an increased likelihood of employing a precooling strategy (OR 2.33; $\mathrm{p}=0.015$ ), while those from South America showed a reduced likelihood (OR 0.11; $\mathrm{p}<0.001)$. The multiple analyses showed that the likelihood of using precooling was higher in women (OR 1.92; $\mathrm{p}=0.014)$ and in athletes from Africa (OR 2.44; $\mathrm{p}=0.035$ ) and Asia (OR 2.66; $p=0.006$ ), but lower in South American athletes (OR 0.12; $<<0.001)$.

Athletes competing in endurance events demonstrated a lower likelihood of using a planned fluid consumption strategy in the simple and multiple analysis models (OR $0.30 ; \mathrm{p}<0.001$ ) (table 6).

The simple heat stress prevention model analyses revealed that sex (females: $14.8 \%$ and males: 5.2\%) (OR 2.61; $\mathrm{p}=0.026)$, home continent $(\mathrm{p}=0.024)$ and a previous diagnosis of EHI (OR 8.22; $\mathrm{p}<0.001$ ) were associated with adopting a strategy which included: heat acclimatisation, precooling and a fluid consumption strategy (table 7). Athletes from South America (OR 0.12; $\mathrm{p}=0.042$ ) were less likely to adopt such a strategy. In the multiple model, only athlete sex (OR 2.77; $\mathrm{p}=0.024)$ and a previous diagnosis of EHI (OR 8.64; $\mathrm{p}<0.001)$ remained.

\section{DISCUSSION}

The aim of this study was to evaluate the history of EHI and preparedness of athletes competing in the 2015 IAAF World Athletics Championships in Beijing under potentially hot/humid ambient conditions, and to identify the factors associated with adopting different heat stress prevention strategies using a precompetition questionnaire. To the best of our knowledge, this is the first report describing the preparation of elite-level athletes competing in such a high-profile event. Our results indicate that approximately half of the athletes participating in the study had previously experienced heat illness symptoms (eg, cramping, severe headaches) and $8.5 \%$ had been diagnosed with EHI, most commonly dehydration. Only $15 \%$ of athletes reported having prepared specifically for the championships by undertaking heat training regimens (mean duration: $\sim 20$ days). It was also observed that precooling in a variety of forms was adopted by half of the athletes. The volume of fluids planned on being consumed during competition varied considerably, with field and sprint athletes mostly planning on consuming $0.5-1 \mathrm{~L}$, middle-distance and long-distance athletes a mixture of volumes, and decathletes/heptathletes more than $2 \mathrm{~L}$. The composition of the fluids consumed was mainly water with some electrolytes. A quarter of the athletes planned on using one recovery strategy and another quarter a combination of strategies (eg, massage, stretching, cold-water immersion). These data indicate that fluid consumption was an integral part of the approach for almost all athletes (96\%) competing at the World Championships, followed by precooling (52\%) and training in the heat $(15 \%)$. The most common explanatory variables associated with adopting multiple heat stress prevention strategies were a previous diagnosis of EHI and the sex of the athlete, with women displaying a higher likelihood.

Our data demonstrate a personal history of cramping as being the most prevalent heat illness symptom reported, with a relatively low incidence of having previously been diagnosed with severe EHI (ie, heat stroke; table 2). During the 2015 Championships, five of the athletes participating in the study were reported as having experienced issues related to EHI. Of these athletes, two had previously experienced symptoms related to EHI during training and/or competing in the heat; however, none had been diagnosed with EHI. Three of the athletes participated in endurance events, one in a middle-distance race and the other in a field event. Two athletes had prepared by heat acclimatising, three had a precooling strategy, all had a hydration plan, and four a recovery strategy. Interestingly, the two athletes who had previously experienced EHI symptoms are the ones who heat acclimatised. Given that several risk factors are linked with the development of EHI-environmental factors, medications, drug use, compromised health status and genetic conditions-it is difficult to identify why these athletes

Table 4 Explanatory models for training in the heat (ie, heat acclimatisation/acclimation) prior to the 2015 IAAF World Championships presented as ORs $(95 \% \mathrm{Cl})$ calculated by simple and multiple logistic regression analyses

\begin{tabular}{|c|c|c|}
\hline & \multicolumn{2}{|l|}{$95 \%$ OR } \\
\hline & \multicolumn{2}{|c|}{ Prechampionship heat acclimatisation } \\
\hline & Simple models & Multiple model \\
\hline Sex & $1.90(1.01$ to 3.56$)(p=0.045)$ & $1.97(1.02$ to 3.82$)(p=0.043)$ \\
\hline Age & NS & \\
\hline Continent (reference: Europe) & NS $(p=0.057)$ & \\
\hline $\begin{array}{l}\text { Human Development Index (reference: very high-level countries) } \\
\text { Lower developmental levels (very low-level, low-level, high-level countries) }\end{array}$ & NS & \\
\hline $\begin{array}{l}\text { Event category (reference: speed/power events) } \\
\text { Endurance events }\end{array}$ & NS & \\
\hline Prechampionships medical support available & NS & \\
\hline Experience of heat-related symptoms & $1.88(1.01$ to 3.51$)(p=0.048)$ & \\
\hline Previous EHI diagnosis & 7.27 (3.11 to 16.97$)(p<0.001)$ & $7.47(3.15$ to 17.69$)(p<0.001)$ \\
\hline
\end{tabular}


Table 5 Explanatory models for using a precooling strategy during the 2015 IAAF World Championships presented as ORs (95\% CI) calculated by simple and multiple logistic regression analyses

\begin{tabular}{|c|c|c|}
\hline & \multicolumn{2}{|l|}{$95 \%$ OR } \\
\hline & \multicolumn{2}{|c|}{ In-championship use of precooling strategy } \\
\hline & Simple models & Multiple model \\
\hline Sex & $1.64(1.04$ to 2.58$)(p=0.034)$ & $1.92(1.14$ to 3.23$)(p=0.014)$ \\
\hline Age & NS & \\
\hline Continent (reference: Europe) & $\mathrm{p}<0.001$ & $\mathrm{p}<0.001$ \\
\hline Africa & $2.02(0.91$ to 4.53$)(p=0.086)$ & $2.44(1.07$ to 5.59$)(p=0.035)$ \\
\hline Asia & $2.33(1.18$ to 4.62$)(p=0.015)$ & $2.66(1.32$ to 5.36$)(p=0.006)$ \\
\hline Australia & $3.31(0.64$ to 17.20$)(p=0.154)$ & $2.92(0.55$ to 15.44$)(p=0.206)$ \\
\hline North America & $1.45(0.71$ to 2.96$)(p=0.305)$ & $1.51(0.74$ to 3.12$)(p=0.261)$ \\
\hline South America & $0.11(0.05$ to 0.29$)(p<0.001)$ & $0.12(0.05$ to 0.30$)(p<0.001)$ \\
\hline $\begin{array}{l}\text { Human Development Index (reference: very high-level countries) } \\
\text { Lower developmental levels (very low-level, low-level, high-level countries) }\end{array}$ & $2.44(1.53$ to 3.88$)(p<0.001)$ & \\
\hline $\begin{array}{l}\text { Event category (reference: speed/power events) } \\
\text { Endurance events }\end{array}$ & $1.72(1.09$ to 2.72$)(p=0.020)$ & \\
\hline Prechampionships medical support available & NS & \\
\hline Experience of heat-related symptoms & NS & \\
\hline Previous EHI diagnosis & $2.73(1.15$ to 6.48$)(p=0.023)$ & \\
\hline
\end{tabular}

$\mathrm{Cl}$, confidence interval; EHI, exertional heat illness; IAAF, International Association of Athletics Federations; OR, odds ratio.

Table 6 Explanatory models for using a fluid consumption strategy during the 2015 IAAF World Championships presented as ORs $(95 \% \mathrm{Cl})$ calculated by simple and multiple logistic regression analyses

\begin{tabular}{|c|c|c|}
\hline & \multicolumn{2}{|l|}{$95 \%$ OR } \\
\hline & \multicolumn{2}{|c|}{ In-championship use of hydration strategy } \\
\hline & Simple models & Multiple model \\
\hline Sex & NS & \\
\hline Age & NS & \\
\hline Continent (reference: Europe) & NS & \\
\hline $\begin{array}{l}\text { Human Development Index (reference: very high-level countries) } \\
\text { Lower developmental levels (very low-level, low-level, high-level countries) }\end{array}$ & NS $(p=0.056)$ & \\
\hline $\begin{array}{l}\text { Event category (reference: speed/power events) } \\
\text { Endurance events }\end{array}$ & $0.27(0.15$ to 0.50$)(p<0.001)$ & $0.27(0.15$ to 0.50$)(p<0.001)$ \\
\hline Prechampionships medical support available & NS & \\
\hline Experience of heat-related symptoms & NS & \\
\hline Previous EHI diagnosis & NS & \\
\hline
\end{tabular}

$\mathrm{Cl}$, confidence interval; EHI, exertional heat illness; IAAF, International Association of Athletics Federations; OR, odds ratio.

experience EHI symptoms, despite preparing for the championships by training in the heat. Although there may be an increased likelihood of experiencing EHI when participating in high-intensity endurance events, our data suggest that athletes in shorter races and field events are also likely to be susceptible to EHI. Additional research is thus warranted to determine the potential markers indicative of EHI predisposition.

Nevertheless, $<2 \%$ of the athletes participating in the study were reported as having experienced EHI symptoms. This may relate to the WBGT remaining between $23^{\circ} \mathrm{C}$ and $28^{\circ} \mathrm{C}$ during the championships, a range associated with a high but not extreme $\left(\geq 28^{\circ} \mathrm{C}\right)$ risk for EHI. ${ }^{16}{ }^{17}$ The WBGT is an environmental heat stress index and not a representation of human heat strain. As such, it may not represent the environmental conditions in which the limit of compensation is exceeded in different events, which depends on several factors (eg, metabolic heat production, athlete morphology, acclimatisation state and clothing). ${ }^{8}$ Nevertheless, these data are in line with a previous surveillance study examining the risk of heat illness in professional beach volleyball over a 3 -year period. ${ }^{18}$ The authors observed that the risk of significant heat illness was very low, even though hot and humid conditions were encountered frequently, with only three cases of a medical forfeiture related to heat stress. This most likely reflects the high level of fitness of elite athletes and some degree of adaptation to heat.

It has been suggested that heat acclimatisation is the most important intervention one can adopt to reduce physiological strain and optimise performance is to heat. ${ }^{8}$ Heat acclimatisation reduces the risk of EHI, as well as induces physiological adaptations that improve thermoregulation, attenuate physiological strain and improve aerobic performance in warm/hot environments. ${ }^{19}{ }^{20}$ It is interesting to note that a similar or even slightly lower per cent of middle-distance and long-distance athletes reported having specifically prepared for the championships by 
Table 7 Explanatory models for the use of all three heat stress prevention strategies (ie, training in the heat, planning to use a precooling method and fluid consumption strategy) prior to and during the 2015 IAAF World Championships presented as ORs (95\% CI) calculated by simple and multiple logistic regression analyses

\begin{tabular}{|c|c|c|}
\hline & \multicolumn{2}{|l|}{$95 \%$ OR } \\
\hline & \multicolumn{2}{|c|}{ In-championship use of heat stress prevention strategies } \\
\hline & Simple models & Multiple model \\
\hline Sex & $2.61(1.12$ to 6.06$)(p=0.026)$ & $2.77(1.14$ to 6.68$)(p=0.024)$ \\
\hline Age & NS & \\
\hline Continent (reference: Europe) & $p=0.024$ & \\
\hline Africa & $0.46(0.10$ to 2.19$)(p=0.331)$ & \\
\hline Asia & $0.28(0.06$ to 1.27$)(p=0.099)$ & \\
\hline Australia & $4.45(0.94$ to 21.03$)(p=0.060)$ & \\
\hline North America & $1.17(0.41$ to 3.35$)(p=0.768)$ & \\
\hline South America & $0.12(0.02$ to 0.93$)(p=0.042)$ & \\
\hline $\begin{array}{l}\text { Human Development Index (reference: very high-level countries) } \\
\text { Lower developmental levels (very low-level, low-level, high-level countries) }\end{array}$ & NS & \\
\hline $\begin{array}{l}\text { Event category (reference: speed/power events) } \\
\text { Endurance events }\end{array}$ & NS & \\
\hline Prechampionships medical support available & NS & \\
\hline Experience of heat-related symptoms & NS & \\
\hline Previous EHI diagnosis & $8.22(3.20$ to 21.16$)(p<0.001)$ & $8.64(3.26$ to 22.85$)(p<0.001)$ \\
\hline
\end{tabular}

training in the heat, relative to other event categories. Given that longer duration events are the ones for which heat acclimatisation is most highly recommended, ${ }^{8}$ it was anticipated that a greater fraction of these athletes would have acclimatised. However, given that our data were separated by continent rather than country, it was not possible to determine precisely where the athletes originated from. It is thus conceivable that many athletes live and train in warm/hot summer conditions and did not report having specifically heat acclimatised. Although less than one-fifth of all athletes surveyed reported undertaking a heat acclimatisation regimen, few experienced EHI during the championships while competing in the $\sim 28^{\circ} \mathrm{C}$ and $\sim 55 \%$ relative humidity conditions. While these conditions can be considered warm to hot, they may not be overly oppressive for well-trained individuals by virtue of regularly increasing thermoregulatory strain when training at high intensities, and consequently developing some heat adaptation. ${ }^{19}$

Indeed, well-trained individuals exercising at the same relative intensity, but at a higher metabolic rate than untrained individuals, experience a greater rate of heat storage, ${ }^{2122}$ but fatigue at similar ${ }^{23} 24$ or higher core temperatures. ${ }^{25} 26$ Accordingly, adaptations related to regular high-intensity training may allow for higher rates of whole-body heat accumulation before a reduction in work rate occurs. ${ }^{27}$ Moreover, aerobically fit individuals heat acclimatise more rapidly than those who are less fit and may have a reduced susceptibility to heat injury/illness (Gardner et al, 1996). Given that short-term heat acclimatisation (<7 days) provides some performance-enhancing benefits, ${ }^{28}$ athletes competing in the World Championships may have adapted to the heat during outdoor training sessions in the lead-up to their event while in Beijing, thus reducing the susceptibility to EHI and optimising performance. In the current study, the variable associated with a greater likelihood of training in the heat in preparation for the championships was a previous diagnosis of EHI, whereas originating from South America was associated with a lower likelihood (table 4). These observations highlight the complexity and numerous factors that influence the preparation strategy of elite athletes. Therefore, it seems important that all athletes receive appropriate information ahead of a major event expected to take place in hot and/or humid conditions regarding various preparation strategies, regardless of their country of origin, sex and EHI history.

Precooling is an intervention that is becoming increasingly popular with athletes looking to reduce thermal strain, minimise fatigue and accelerate postexercise recovery. By cooling the skin prior to competition (eg, ice vest), athletes can reduce cardiovascular strain for a short period after the onset of exercise in the heat. ${ }^{29}$ When whole-body cooling (eg, cold-water immersion) is implemented, a decrease in organ and skeletal muscle temperature occurs. Although precooling in its various forms (ie, internal and external) is interesting and appears to have been adopted by several athletes at the 2015 World Championships, the effectiveness and practicality of various cooling techniques, along with the physiological mechanisms underpinning the improvements in performance, require further investigation. ${ }^{29} 30$ During the championships, the factors associated with a higher likelihood of precooling were a previous diagnosis of $\mathrm{EHI}$, home continent (Africa and Asia), a lower level on the HDI, sex (females $58 \%$ vs males $48 \%$ ) and participating in endurance events (table 5). In addition to showing a lower likelihood of heat acclimatisation, athletes from South America also showed a very low likelihood of using precooling techniques. This most likely reflects a combination of factors, from the number of athletes participating in endurance events, to the sex of these athletes, and a previous diagnosis of EHI. Accordingly, further research is required to better understand how these factors, along with socioeconomic considerations, interact to influence the preparation and use of various heat stress countermeasures in athletes from different continents, as well as specific countries in the lead-up to a major championships.

Athletes performing exercise in warm/hot and humid environments have elevated sweat rates which can result in large body water and electrolyte deficits, exacerbating the performance impairments associated with heat stress. ${ }^{5}$ Athletes competing in the championships may have been aware of the impact that hydration status may have on performance and recovery, as more 
than $80 \%$ had a fluid consumption strategy (table 3). This was especially noticeable in the decathletes and heptathletes spending the better part of an entire day on the track and field, consuming water, as well as electrolytes and carbohydrates. However, it is not possible to determine from the current data if the planned hydration strategy of the athletes was different from their usual strategy in cooler environments. Interestingly, endurance athletes had a lower likelihood of adopting a fluid consumption strategy than speed/power athletes (table 6). However, this most likely relates to the decathletes and heptathletes having been included in the speed/power athlete category of the explanatory models and the nature of the question, which for some could have included the warm-up and cool down (eg, sprints).

When combined into a heat stress prevention strategy using training in the heat, precooling and having a fluid consumption strategy, South American athletes appeared to be at a very low likelihood of adopting such a strategy (table 7). However, the previous diagnosis of $\mathrm{EHI}$ increased the likelihood of using a combined heat stress prevention strategy eightfold.

Recovery between events/heats during an athletics competition is essential for optimising physical and mental performance. With a host of recovery options such as water immersion, compression clothing, cryotherapy, sports massage and electrostimulation, ${ }^{31-34}$ it is not surprising to have observed that $25 \%$ of the athletes use one recovery strategy and $\sim 63 \%$ at least two recovery strategies (table 3). Although there exist many potential strategies to use during competition, the ones most frequently employed were massage, active recovery, stretching and cold-water immersion.

In summary, only $15 \%$ of the athletes surveyed prepared by training in the heat ahead of the 2015 IAAF World Championships in which hot/humid conditions were expected. Approximately half had a precooling strategy, $96 \%$ a fluid consumption strategy and over $89 \%$ a recovery strategy. Although most athletes did not heat acclimatise prior to the championships, $<2 \%$ experienced EHI symptoms. This may be attributed to their high level of fitness, partly conferring adaptations similar to heat acclimatisation, and to the other strategies and interventions employed during competition. Having previously experienced $\mathrm{EHI}$ and being female were strongly associated with using one or multiple heat stress prevention strategies. Nevertheless, it is recommended that information regarding heat acclimatisation as the primary countermeasure to protect athlete health and optimise performance be disseminated ahead of competitions to be held in hot/humid conditions to allow for adequate preparation.

\section{Study strengths and limitations}

The major strength of this study is that, to the best of our knowledge, it is the first to examine the history of EHI and preparedness of elite-level athletes competing in a World Championships in the heat, as well as to evaluate the predictors associated with using heat stress preventing strategies. It should be noted that there exist differences between a clinical diagnosis of EHI and 'feeling sick/uncomfortable in the heat'. Since these concepts are not synonymous, the diagnostic criteria for EHI at major athletics competitions should be agreed on and uniformly applied. Although the overall response rate was relatively low (32.1\%), the survey was designed to minimally disrupt the athletes. Moreover, the study was conducted during a period of an intense doping debate in athletics, which may have led to some athletes being reluctant to answer health/medical questionnaires. Accordingly, the response rate can be regarded as acceptable. Additional insights regarding the completion of this study are addressed in a companion paper. ${ }^{35}$

\section{What is already known on this topic?}

- Specific interventions such as heat acclimatisation, precooling and adopting a hydration strategy allow for optimising performance when competing in hot/humid environmental conditions.

- Athletic events undertaken in the heat increase the risk of exertional heat illness through the development of hyperthermia and severe dehydration.

\section{What are the new findings?}

- Only $15 \%$ of athletes heat acclimatised ahead of the 2015 IAAF World Championships in which hot/humid conditions were expected, $\sim 50 \%$ had a pre-cooling strategy, $96 \%$ a fluid consumption strategy and over $89 \%$ a recovery strategy.

- A previous diagnosis of exertional heat illness and the female sex were associated with an increased likelihood of using one or multiple heat stress prevention strategies.

\section{How might it impact clinical practice in the near future?}

- Information regarding heat acclimatisation as the primary countermeasure to protect athlete health and optimise performance should be provided to the athletes and their support staff ahead of competitions to be held in hot/humid conditions to allow for adequate preparation.

- Athletes previously experiencing heat illness symptoms and those having been diagnosed with exertional heat illness are more likely to consider heat acclimatisation prior to competing under heat stress.

Twitter Follow Julien Périard @DrJPeriard, Sébastien Racinais@SebRacinais, Jenny Jacobsson @Jenny_Jacobsson and Juan Manuel Alonso @DrJuanMAlonso

Acknowledgements The authors wish to thank all the national team athletes completing the questionnaire, as well as Anna Kochergina, Khouloud Mtiba, Tingting Lin for translating the questionnaires. They also want to express their recognition to Beijing 2015 Local Organisation Medical Managers for their commitment and assistance in the implementation of this study, as well as to the Physicians who contributed to the study with the thorough documentation of all medical encounters during the championships. Their research group further wishes to recognise the IAAF Medical and Anti-Doping Commission and Department for their endorsement and support.

Contributors JDP, SR and J-MA made substantial contributions to the conception of the study. JDP, SR, J-MA, TT and ÖD made substantial contributions to the study design. J-MA, TT, ÖD, AS, JJ, VB and KH were involved in data collection. JDP, TT, $O D D, A S, J J, V B$ and $K H$ were involved in the analysis of the data. All authors made substantial contributions to data interpretation. JDP made the substantial contribution to the drafting and writing of the manuscript. All authors were involved in the revising of the manuscript and gave final approval of the version to be published.

Competing interests None declared.

Ethics approval The study was approved by the Anti-Doping Laboratory Qatar Institutional Review Board and conformed to the current Declaration of Helsinki guidelines.

Provenance and peer review Not commissioned; externally peer reviewed. 
Open Access This is an Open Access article distributed in accordance with the Creative Commons Attribution Non Commercial (CC BY-NC 4.0) license, which permits others to distribute, remix, adapt, build upon this work non-commercially, and license their derivative works on different terms, provided the original work is properly cited and the use is non-commercial. See: http://creativecommons.org/ licenses/by-nc/4.0/

\section{REFERENCES}

1 Weather. Weather underground. Beijing, China, 2016. https://www.wunderground. com/history/DailyHistory.html?req_city=Beijing\&req_statename=China (accessed 20 Feb 2016).

2 Racinais S, Oksa J. Temperature and neuromuscular function. Scand J Med Sci Sports 2010;20(Suppl 3):1-18

3 Périard JD, Cramer MN, Chapman PG, et al. Cardiovascular strain impairs prolonged self-paced exercise in the heat. Exp Physiol 2011;96:134-44.

4 Cheuvront SN, Kenefick RW, Montain SJ, et al. Mechanisms of aerobic performance impairment with heat stress and dehydration. J App/ Physiol 2010;109:1989-95.

5 Sawka MN, Cheuvront SN, Kenefick RW. Hypohydration and human performance: impact of environmental and physiological mechanisms. Sports Med 2015;45:51-60.

6 Leon LR, Bouchama A. Heat stroke. Compr Physiol 2015;5:611-47.

7 Casa DJ, DeMartini JK, Bergeron MF, et al. National Athletic Trainers' Association position statement: exertional heat illnesses. J Athl Train 2015;50:986-1000.

8 Racinais S, Alonso JM, Coutts AJ, et al. Consensus recommendations on training and competing in the heat. Scand J Med Sci Sports 2015;25(Suppl 1):6-19.

9 Bergeron MF, Bahr R, Bartsch P, et al. International Olympic Committee consensus statement on thermoregulatory and altitude challenges for high-level athletes. Br J Sports Med 2012:46:770-9.

10 Byrne C, Lee JK, Chew SA, et al. Continuous thermoregulatory responses to mass-participation distance running in heat. Med Sci Sports Exerc 2006;38:803-10.

11 Ely MR, Cheuvront SN, Roberts WO, et al. Impact of weather on marathon-running performance. Med Sci Sports Exerc 2007;39:487-93.

12 Timpka T, Alonso JM, Jacobsson J, et al. Injury and illness definitions and data collection procedures for use in epidemiological studies in Athletics (track and field): consensus statement. Br J Sports Med 2014;48:483-90.

13 Alonso JM, Edouard P, Fischetto $G$, et al. Determination of future prevention strategies in elite track and field: analysis of Daegu 2011 IAAF Championships injuries and illnesses surveillance. Br J Sports Med 2012;46:505-14.

14 Alonso JM, Jacobsson J, Timpka T, et al. Preparticipation injury complaint is a risk factor for injury: a prospective study of the Moscow 2013 IAAF Championships. Br J Sports Med 2015;49:1118-24.

15 HDI. Human Development Index (HDI). Human Development Reports 2015. United Nations Development Programme. http://hdr.undp.org/en/content/humandevelopment-index-hdi (accessed 1 Apr 2016).

16 Armstrong LE, Casa DJ, Millard-Stafford M, et al., American College of Sports Medicine. American College of Sports Medicine position stand. Exertional heat illness during training and competition. Med Sci Sports Exerc 2007:39:556-72.

17 Binkley HM, Beckett J, Casa DJ, et al. National athletic trainers' association position statement: exertional heat illnesses. J Ath/ Train 2002;37:329-43.

18 Bahr R, Reeser JC. New guidelines are needed to manage heat stress in elite sports -the Federation Internationale de Volleyball (FIVB) Heat Stress Monitoring Programme. Br J Sports Med 2012;46:805-9.

19 Périard JD, Racinais S, Sawka MN. Adaptations and mechanisms of human heat acclimation: applications for competitive athletes and sports. Scand J Med Sci Sports 2015;25:20-38.

20 Périard JD, Travers GJS, Racinais $S$, et al. Cardiovascular adaptations supporting human exercise-heat acclimation. Auton Neurosci 2016;196:52-62.

21 Mora-Rodriguez R, Del Coso J, Hamouti N, et al. Aerobically trained individuals have greater increases in rectal temperature than untrained ones during exercise in the heat at similar relative intensities. Eur J App/ Physiol 2010;109:973-81.

22 Jay 0 , Bain AR, Deren TM, et al. Large differences in peak oxygen uptake do not independently alter changes in core temperature and sweating during exercise. Am J Physiol Regul Integr Comp 2011;301:R832-41.

23 Sawka MN, Young AJ, Latzka WA, et al. Human tolerance to heat strain during exercise: influence of hydration. J App/ Physiol 1992;73:368-75.

24 Périard JD, Caillaud C, Thompson MW. The role of aerobic fitness and exercise intensity on endurance performance in uncompensable heat stress conditions. Eur J Appl Physiol 2012;112:1989-99.

25 Cheung SS, McLellan TM. Heat acclimation, aerobic fitness, and hydration effects on tolerance during uncompensable heat stress. J App/ Physiol 1998;84:1731-9.

26 Selkirk GA, McLellan TM. Influence of aerobic fitness and body fatness on tolerance to uncompensable heat stress. J Appl Physiol 2001;91:2055-63.

27 Mora-Rodriguez R. Influence of aerobic fitness on thermoregulation during exercise in the heat. Exerc Sport Sci Rev 2012;40:79-87.

28 Garrett AT, Creasy R, Rehrer NJ, et al. Effectiveness of short-term heat acclimation for highly trained athletes. Eur J Appl Physiol 2012;112:1827-37.

29 Wegmann M, Faude 0, Poppendieck W, et al. Pre-cooling and sports performance: a meta-analytical review. Sports Med 2012;42:545-64.

30 Jones PR, Barton C, Morrissey D, et al. Precooling for endurance exercise performance in the heat: a systematic review. BMC Med 2012;10:1-19.

31 Engel FA, Holmberg HC, Sperlich B. Is there evidence that runners can benefit from wearing compression clothing? Sports Med 2016. DOI 10.1007/s40279-016-0546-5

32 Bleakley CM, Bieuzen F, Davison GW, et al. Whole-body cryotherapy: empirical evidence and theoretical perspectives. Open Access J Sports Med 2014;5:25-36.

33 Weerapong P, Hume PA, Kolt GS. The mechanisms of massage and effects on performance, muscle recovery and injury prevention. Sports Med 2005;35:235-56.

34 Kovacs MS, Baker LB. Recovery interventions and strategies for improved tennis performance. Br J Sports Med 2014;48(Suppl 1):i18-21.

35 Timpka T, Jacobsson J, Bargoria V, et al. Pre-participation predictors for championship injury and illness: cohort study at the Beijing 2015 IAAF Championships. Br J Sports Med 2016; in press. 